\title{
Do pioneer species enhance early performance of native species in subtropical shrublands? An examination involving six native species in South China
}

\author{
S. Yuan ${ }^{1,2,3,5}$, N. Liu ${ }^{2,3}$, H. Ren ${ }^{2,3}$, H. Zhang 4 and J. Wang ${ }^{2,3}$ \\ ${ }^{1}$ Guangdong polytechnic of Environmental Protection Engineering, Foshan, 528216, China \\ ${ }^{2}$ Key Laboratory of Vegetation Restoration and Management of Degraded Ecosystems, Guangzhou, China \\ ${ }^{3}$ South China Botanical Garden, Chinese Academy of Sciences, Guangzhou, China \\ ${ }^{4}$ Guangdong Provincial Academy of Environmental Sciences, Guangzhou, China \\ ${ }^{5}$ Corresponding Author. Tel: +86-15013168122, Fax:+86-21-57643271,E-mail: yuansf-007@163.com
}

Key words: Facilitation, Fern, Leaf water potential, Soil nutrient, Soil water content, Succession.

\begin{abstract}
This paper examines the following questions: (1) Do early pioneer species have a greater impact on the survival and growth of different successional native trees compared to the shrub Rhodomyrtus tomentosa? (2) Do canopy treatments affect soil nutrients and light availability? (3) What is the mechanism underlying the interaction between nurse species and target species? Degraded shrubland sites (Heshan, Guangdong, China), under moist subtropical conditions were studied. About 1-yearold seedlings of Pinus massoniana, Schima wallichii, Schefflera heptaphylla, Castanopsis hystrix, Cryptocarya chinensis and Castanea chinensis were transplanted under the canopy of $R$. tomentosa, Dicranopteris dichotoma and in open interspaces without vegetation. Survival and growth were recorded from the first growing season after planting. Leaf gas exchange, water potential, soil physicochemical characters and irradiation were then measured. Canonical redundancy analyses (RDA) were used to evaluate the relationships between environmental factors and seedling survival and growth conditions. Both $R$. tomentosa and $D$. dichotoma canopy treatment facilitated seedling survival and growth either directly or indirectly. Irradiance/radiation was considered the most important resource (factor) for seedling growth in subtropical regions, however, soil nutrients and species are yet to be examined simultaneously with irradiance/radiation under field conditions. We conclude that early successional species facilitates the survival and growth of late successional species in subtropical shrublands. However, further predictions of successional trajectories remain elusive and are influenced by stochastic processes, including arrival order, shade tolerance, physiological character of the colonizing species and their competitive interactions.
\end{abstract}

Abbreviations: $A$-Net photosynthesis, AK-Soil Available Potassium, Amax-Light-saturated maximum photosynthesis, AP-Soil Available Phosphorus, $A Q E$-Apparent Quantum Efficiency, CAS-Chinese Academy of Sciences, CERN-Chinese Ecological Research Network, C.V. - coefficient of variation, DT-D. dichotoma treatment, $\mathrm{K}$-total soil potassium, $L C P-$ light compensation point, N-total soil nitrogen, NOVAS-Two-Way Analyses of Variance, OT-Open Treatment, P-total soil phosphorus, PARPhotosynthetically Active Radiation, PPFD-Photon Photosynthetic Flux Density, Rd-Dark Respiration Rate, RDA-Canonical Redundancy Analysis. RNE-Neighbor Effect Index, RT-R. tomentosa treatment, SBD-Soil bulk density, SOC-Soil Organic Carbon, SOM-Soil Organic Matter, SWC-Soil Water Content, $\mathrm{T}_{\text {air }}$-air Temperature, $\Psi m d-$-Midday Leaf Water Potential.

\section{Introduction}

Seedling survival is critical in the restoration of many degraded ecosystems. Seedlings are very sensitive to certain conditions, these include; excessive light and extreme temperatures that may damage seedlings; strong, desiccant winds that may snap twigs and exacerbate water stress caused by low rainfall; and seedling's green sprouts that may be grazed by cattle or wild fauna (Bainbridge 1994, Francisco and Pugnaire 2010, Padilla et al. 2011). Seedlings are generally unable to survive these conditions by themselves under disturbed or degraded environments. However, facilitative interactions between nurse species (objects) and target species may ameliorate these threats (Holmgren and Scheffer 2010, Kitzberger et al. 2000). Two types of facilitation have been identified (Bertness and Callaway 1994): (i) direct facilitation-a neighboring plant directly ameliorates the performance of a target plant through mitigation of the physical environment (habitat amelioration); and (ii) indirect facilitation-the net positive effect occurs only in the presence of a third organism, either another plant (competition release) or an animal (biotic refuge, associational avoidance or predation refuge) (Anthelmea and Michalet 2009).

Restoration practices of seedling transplantation in stressful environments are often chancy due to low seedling survival rate. Several procedures, such as various artificial shading and natural plants shading have been developed to provide seedlings with better protection (Padilla et al. 2011, ReyBenayas 1998, Yang et al. 2010). Generally, most nurse species are mature trees, shrubs and perennial plants. However, 
grass, rocks and cacti could also be used as nurse objects (Drezner 2007). However given the merits of low cost, easiness, and high efficiency, using a naturally occurring species as a nurse plant is by far the most common practice (Yang et al. 2009, Yang et al. 2010). In particular, in many open and arid landscapes, these nurse species could ameliorate the problems of water and light availability beneath their canopies as well as create "islands of fertility" (i.e., patches of increased nitrogen availability) through the decomposition of leaf litter and the trapping of wind-blown litter from the surrounding area (Cushman et al. 2010). Despite this, the nursing effectiveness of different successional species in moist subtropical environments has not been examined.

In degraded moist subtropical environments, plants such as shrubs (Rhodomyrtus tomentosa, Melastoma candidum) and ferns (Dicranopteris dichotoma) are considered as pioneer species (Yang et al. 2010). Certain pioneer species have large canopies which can protect seedlings against damage from biotic (Anthelmea and Michalet 2009, Chaar et al. 2008, Sharrow 2001) and abiotic factors (Bainbridge 1994); hence, a wide range of species have lower survival rates in open areas compared to canopy protected areas (Castro et al. 2004, Gómez-Aparicio et al. 2004). This is due to the lack of buffering effects of shrub or tree nurse canopies which abate high radiation and evapotranspiration (Rodríguez-Calcerrada et al. 2008). Until recently, the facilitation of one successional stage by the preceding stage has been recognized, albeit underestimated, and several theories on succession have been demonstrated in a number of ecosystems (Brooker et al. 2008). For example, previous studies suggests that shadetolerant species and late-successional shrubs have a greater positive effect in response to nurse species compared to pioneer shrubs and shade-intolerant pine trees in forest ecosystems (Gómez-Aparicio et al. 2004). Thus, restoration ecologists and land managers should take facilitation into account, not only because of the critical role of nurse species in restoring the characteristics and functions of the original system (Bruno et al. 2003), but also because of its function of driving succession in many habitats, particularly in disturbed sites (Anthelmea and Michalet 2009, Brooker et al. 2008).

Forest restoration in degraded moist subtropical environments is particularly difficult because of resource unavailability and the lack of native seed sources. These barriers result in self-perpetuating systems that hardly return to the structure and complexity of the original mature community (Duan et al. 2008, Ren et al. 2010). In addition, extreme temperature and irradiation in summer and droughts in the fall and winter may increase the uncertainty and complexity of the procedure of succession and restoration (Peng et al. 2005). Under these limiting conditions, pioneer species canopy could provide suitable micro-sites for seedlings survival and growth.

In our previous published work, the shrub Rhodomyrtus tomentosa was found to facilitate seedling survival and growth of native climax woody species. The nursing effects depended more on canopy shade than on soil amelioration and was positively correlated with shade tolerance of the target species (Yang et al. 2010). However, previous research involving nurse species and target species has been restricted to a single nurse species and a few climax species, respectively. Their effectiveness in improving the survival of different successional-stage species in moist subtropical climates has not been examined. Thus, we introduced a dominant fern Dicranopteris dichotoma as a potential nurse species to assess its contribution to enhancing early seedling survival and growth of a wide range of successional native trees commonly used in restoration programs in degraded moist subtropical regions of southern China. In this study, we transplanted the seedlings of six target species representing three different succession-stages of south subtropical vegetation under the canopy of $R$. tomentos $a$ and $D$. linearis and in an open area. We assumed that changes in microtopography have no effect on plant growth. Specifically, we tried to answer the following questions: (1) Do pioneer species enhance the survival and growth of different successional native trees? (2) Do pioneer species affect soil nutrients and light availability? (3) What causes the specific interactions between nurse species and target species? We assume that (1) The two pioneer nursing species, Rhodomyrtus tomentosa and Dicranopteris linearis, have the potential of facilitating the survival rates and growth of native trees. Such influence might be related to certain subcessional-stage of the target plants; (2) The canopy treatments of the two pioneer species would substantially reduce the radiation reaching the soil surface and would in turn ameliorate the physicochemical characters of the soil under the canopies; (3) Given that canopy treatments cultivate specific micro-environment, the changes in environmental factors, especially radiation, might play a key role in determining the interaction mechanisms between nursing and target species.

\section{Materials and methods}

\section{Study area and species}

The study site was located at the shrubland site in the Heshan National Field Research Station of Forest Ecosystems, Chinese Academy of Science (112 $\left.50^{\prime} \mathrm{E}, 22^{\circ} 34^{\circ} \mathrm{N}\right)$, Heshan City, Guangdong, China. This station (ca. 40 ha) is one of the core stations of the Chinese Ecological Research Network (CERN) of the Chinese Academy of Sciences (CAS). The area has a south subtropical monsoon climate, characterized by hot wet summers and cool dry winters without severe cold. The mean annual temperature is $22.6^{\circ} \mathrm{C}$, and the mean annual precipitation is $1801.1 \mathrm{~mm}$, which mainly occurs from May to September. Under these climate conditions, the potential vegetation is the low subtropical monsoon broad-leaved forest. Under continuous and extended human disturbances, a large portion of forest areas in this region have become a degraded shrubland slope. Shrub and herbaceous species, including $R$. tomentosa, D. dichotoma, Melastoma candidum, Clerodendrum fortunatum and Ilex asprella have taken over most of the hilly land area. The zonal soil is laterite and was formed by desiliconization and aluminium enrichment. It is characterized by low content of required nutrients, lack of organic matter and high acidity $(\mathrm{pH}$ in water $<5.0)$. Our experi- 
ment site occupies about 2 ha in a typical degraded shrubland slope (Yang et al. 2010).

\section{Nurse species}

R. tomentosa and $D$. dichotoma were selected as the nurse plants and were the dominant plants in our experimental site. $R$. tomentosa, as a pioneer shrub in the degraded shrubland slope, is an evergreen shrub growing up to 1-2 $\mathrm{m}$ tall and forming a cushion-shaped canopy (Ren et al. 2010). D. dichotoma is one of the most widely distributed ferns throughout the wet areas of the Old World tropics and subtropics and is intolerant to shade, drought and frost but tolerant to poorly drained and oligotrophic soils. This heliophilous fern is a pioneer species in primary successional sites such as lava flows, mountain ridges, precipices and taluses, and can also colonize secondary successional sites such as landslides, post-agricultural sites, understory environment and degraded forest lands in India, Sri Lanka, Malaysia and China (Russell et al. 1998). In our experiment area, dense, extensive thickets 1.5-2 m high are formed using this fern.

\section{Target species}

The six target species are typical species belonging to three successional stages in the forest ecosystem in the study area and are as follows: Pinus massoniana Lamb (Pinaceae) and Schima wallichii (DC.) Korth. (Theaceae) (early successional tree species), Schefflera heptaphylla (L.) Frodin (Araliaceae) and Castanopsis hystrix (Fagaceae) (mid-successional tree species), Cryptocarya chinensis (Hance) Hemsl. (Lauraceae) and Castanea chinensis (Hance) (Fagaceae) (mature canopy late-successional tree species).

\section{Experimental design}

The experiment was carried out from March 2010 to June 2011. Around 1-year-old seedlings of the six target species were pit-planted under the canopy of $R$. tomentosa ( $R$. tomentosa treatment, RT), D. dichotoma ( $D$. dichotoma treatment, DT) and in open interspaces without vegetation (open treatment, OT). The experiment had a randomized block design (completely randomized design) with three treatments $\times$ six target species $\times$ three replicate plots. In total, 54 plots were utilized in our study. In each plot, 30 individual target species and treatment were planted; a total of 1620 seedlings were planted. All seedlings were purchased from tree seedling nurseries and were grown for the first year in the nursery in $15 \mathrm{~cm}$ deep plastic pots under similar conditions with same appropriate watering and fertilization managements. The size and height of all seedlings were similar (height: $15-20 \mathrm{~cm}$, depending on the species), except $P$. massoniana (height: $5 \mathrm{~cm}$ ). At the time of planting, $R$. tomentos $a$ were about $2 \mathrm{~m}$ in height and $1.5 \mathrm{~m}$ in canopy radius, and $D$. dichotoma were about $1.5 \mathrm{~m}$ in height and $1 \mathrm{~m}$ in canopy radius."

In early September 2011, we continuously recorded the Photosynthetically Active Radiation (PAR) (LI-250 light meter: LI-COR, Lincoln, Nebraska, USA). At the end of the experiment, soil samples were collected from OT, DT and RT from each plot, respectively. To determine soil chemical characteristics, each soil sample consisted of 5 randomly selected soil cores ( $5 \mathrm{~cm}$ diameter) from each plot. Air dried soil samples were passed through a $2 \mathrm{~mm}$ sieve to analyze soil $\mathrm{pH}$, total soil nitrogen $(\mathrm{N})$, total soil phosphorus $(\mathrm{P})$, total soil potassium $(\mathrm{K})$, soil organic matter $(\mathrm{SOM})$, soil organic carbon (SOC), soil available phosphorus (AP) and soil available potassium (AK). For soil physical characteristics measurements, soil samples were gathered from 5 intact soil cores taken randomly from each plot using ring knifes. Soil bulk density (SBD) and soil water content (SWC) were determined by weighing intact soil cores after they were oven-dried at $105^{\circ} \mathrm{C}$. Both soil chemical and physical characteristics were analyzed based on the Handbook of the Chinese Ecosystem Research Network (Liu 1996).

The size of the seedlings was examined 10 days after transplantation as the initial values. First, survival rate was monitored in the middle of May. Afterwards the seedling size and survival were recorded in the middle of the tenth day of each month from August. In addition, seedling size was recorded for the five fixed individuals in each plot. The shoot height of the six target species under the three different treatments was recorded for each plot. Subsequently, the relative neighbor effect index (RNE) was calculated on the basis of the shoot height to examine whether the effect of the nurse plant on the target species was positive $(\mathrm{RNE}<0)$ or negative $(\mathrm{RNE}>0)$ as follows:

$$
\mathrm{RNE}=\left(S_{o}-S_{t}\right) / x \text {; }
$$

where $S_{t}$ and $S_{o}$ are shoot height of DT or RT and OT plots respectively. $x=S_{t}$ when $S_{t}>S_{o} ; x=S_{o}$ when $S_{o}>S_{t}$ (Armas et al. 2004).

At the end of the experiment, the five fixed individuals were harvested and the aboveground biomass and root biomass were determined respectively.

Light-response curves were generated for each species and different treatments for the wet seasons (September, 2010). The light-response curves were developed using near-ambient $\left[\mathrm{CO}_{2}\right]$ of $400 \mu \mathrm{mol} \mathrm{mol}{ }^{-1}$. Gas exchange was measured on one fully expanded leaf per individual plant on the southeast side of each species for the different treatments with a portable photosynthesis system (LI-6400, Li-Cor, Inc) between 10:00 am and 14:00 pm on clear days. The temperature inside the chamber was adjusted to the outside temperature $\left(\mathrm{T}_{\text {air }}\right)$ based on an external sensor attached to the chamber. Ambient light levels (photon photosynthetic flux density, PPFD) were also monitored using a cuvette-mounted sensor at the location of the gas-exchange measurements. The minimum time allowed for reading stabilization at each level of PPFD was $120 \mathrm{~s}$, and the maximum time for saving each reading was $150 \mathrm{~s}$. A flow rate of $500 \mu \mathrm{mol} \mathrm{s}-1$ and a maximum coefficient of variation $(C . V$. ) of $1 \%$ were used. Net photosynthesis $(A)$ was measured as a function of PPFD inside the cuvette based on the following levels: $1500,2000,1800,1600,1400,1200$, $1000,500,300,200,100,50,20$ and $0 \mu \mathrm{mol} \mathrm{m}^{-2} \mathrm{~s}^{-1}$. The 1500 $\mu \mathrm{mol} \mathrm{m}{ }^{-2} \mathrm{~s}^{-1}$ light level was measured prior to the $2000 \mu \mathrm{mol}$ 
$\mathrm{m}^{-2} \mathrm{~s}^{-1}$ level because it is generally recommended to prepare the chamber for light-response curves in $\mathrm{C}_{3}$ plants at 1500 $\mu \mathrm{mol} \mathrm{m}{ }^{-2} \mathrm{~s}^{-1}$ (Li-Cor, Inc., 2003). Photosynthetic parameters were estimated from each light-response curve by fitting a linear regression line between the 0 and $200 \mu \mathrm{mol} \mathrm{m}^{-2} \mathrm{~s}^{-1}$ illumination intensity, with light compensation point $(L C P, \mu \mathrm{mol}$ photons $\mathrm{m}^{-2} \mathrm{~s}^{-1}$ ) determined when $y=0$, dark respiration rate $\left(R d, \mu \mathrm{mol} \mathrm{CO} \mathrm{C}_{2} \mathrm{~m}^{-2} \mathrm{~s}^{-1}\right)$ determined when $x=0$, and apparent quantum efficiency ( $A Q E, \mu \mathrm{mol} \mathrm{CO}_{2} \mu \mathrm{mol}{ }^{-1}$ photons) determined as the slope of the line. Light-saturated maximum photosynthesis (Amax, $\mu \mathrm{mol} \mathrm{m} \mathrm{m}^{-2} \mathrm{~s}^{-1}$ ) was measured based on the PPFD level with the highest $A$ along each response curve. Leaves sampled for each species were measured for midday leaf water potential $(\Psi m d)$ in September 2010, January and June 2011 to determine water stress (PH $\psi$ PROTM Water Potential System, Wesco, Inc.) for seasonal variation.

\section{Statistical analysis}

All results are shown as means $\pm \mathrm{SE}$. We used One-way ANOVA to determine the effects of $R$. tomentosa treatment (RT), D. dichotoma treatment (DT) and open treatment (OT) on seedling survival, growth, photosynthetic performances, leaf water potential and biomass of the target species. To examine the species effect, treatment effect and species $\times$ treatment effects on the soil conditions, two-way analyses of variance (ANOVAS) were performed; the species and treatments were considered as independent variables while the soil conditions were considered as dependent variables. To determine the relationships between survival and growth of seedling and environmental factors, canonical redundancy analyses (RDA) (Lepš and Šmilauer 2003) was used. All data were log-, square root- or arcsine- transformed when necessary to meet the assumptions of the respective analyses. All analyses and drawing were performed using SPSS 13.0, SIGMAPLOT 10.0 and CANOCO 4.5 for windows.

\section{Results}

The survival of the seedlings of the six target species was $50-100 \%$ for all plots. The highest seedling mortality occurred during the first three to five months after transplantation. The shelter of $D$. dichotoma decreased the survival rate of $P$. massoniana in the OT and DT $(P<0.05)$. For $S$. wallichii, the survival rate of the seedlings in OT, DT and RT was $56.8 \%$, $62.2 \%$ and $53.1 \%$, respectively. There were no significant differences in the survival rate of $S$. wallichii among the three treatments. The Castanopsis hystrix seedlings had the highest survival rate (94.8-100\%) among the examined species for the three treatments. The survival rates of S. heptaphylla seedlings in OT, DT and RT were $62.2 \%, 79.9$ and $82.2 \%$ respectively. In addition, the survival rate in OT was higher compared to DT and RT before $28^{\text {th }}$ March; thereafter, it suddenly dropped by $30 \%$. The survival rate of Cryptocarya chinensis seedlings was 78.7-87.2\% for all plots. Compared with the other five species, Castanea chinensis seedlings had the lowest survival rate (50-65.5\%) and the highest mortality occurred in the first few months after transplantation (Fig. 1).

Generally, compared with the initial levels, the shoot height increased by 4, 2, 2, 1.3, 0.8 and 1 time for P. massoniana, S. wallichii, S. heptaphylla, C. hystrix, Cryptocarya chinensis and Castanea chinensis seedlings respectively. The growth of $S$. wallichii was significantly affected by the treatments and the height of the seedlings in the DT and RT were much higher compared to OT treatment $(P<0.05)$. The height of $S$. heptaphylla seedlings in DT and RT reached 57.4 and $45.3 \mathrm{~cm}$ respectively, and they were 1.6 and 1.3 times taller compared to OT treatment, respectively. The Castanea chinensis seedlings in the RT were significantly taller than in
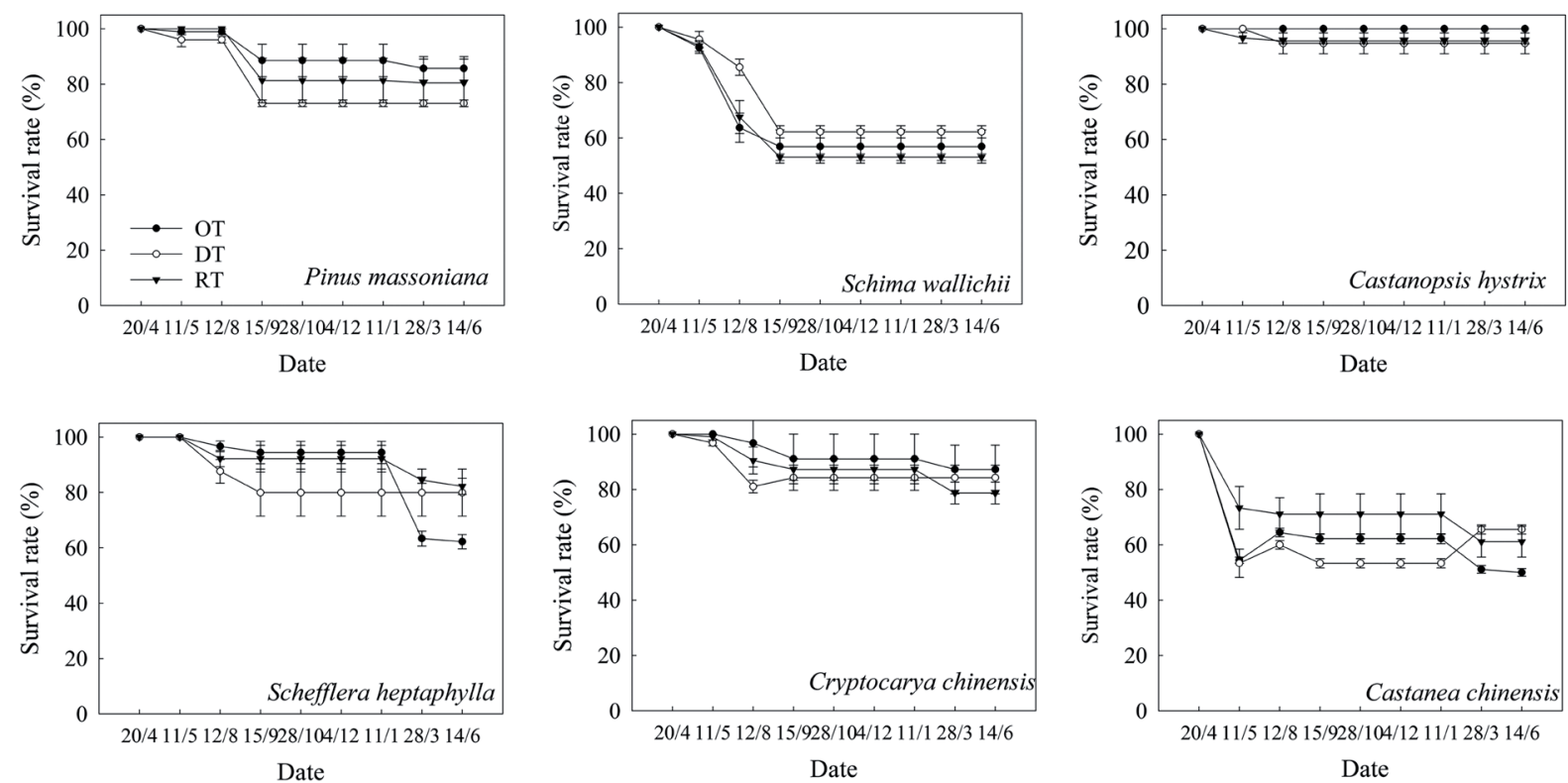

Figure 1. Survival of the six target species seedlings under different treatments with time (vertical bars represent standard errors - SE). 

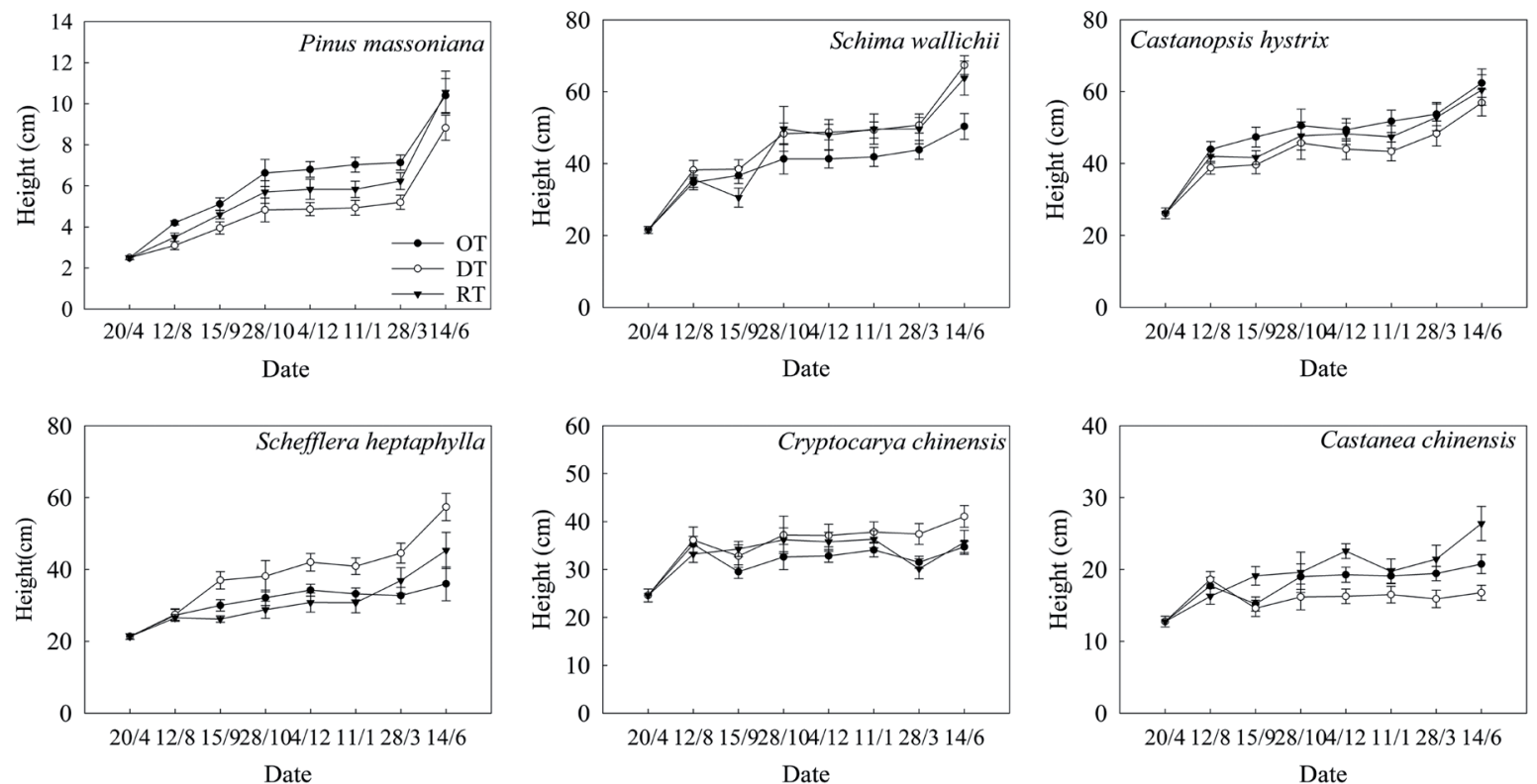

Figure 2. Growth of the six target species seedlings under different treatments with time (vertical bars represent standard errors - SE).

the DT $(P=0.034)$, but there were no significant differences between the heights in the OT and RT or OT and DT treatments. Cryptocarya chinensis seedlings were significantly taller in the DT compared to the OT $(P=0.050)$. The height of Pinus massoniana seedlings in OT, DT and RT showed no significant differences, however, the highest average height occurred in the OT (Fig. 2).

The results showed that the RNE of seedling height was affected by the treatment and that the effect of nurse plants on the target plants varied over time. The seedling height of P. massoniana and C. hystrix showed negative effect in DT and RT during the entire survey period. For $S$. wallichii and Cryptocarya chinensis, DT and RT both facilitated the early growth of the seedlings and their positive effects became more significant with time. For the $S$. heptaphylla seedlings, the interactions between the nurse species and target species were complex; DT facilitated growth but RT inhibited growth. In addition, the positive effect became more significant in the DT plot, while the negative effects of RT became weaker over time. For the Castanea chinensis seedlings, there was a weak negative effect on growth in the DT plots and an enhanced positive effect on growth in the RT plots (Fig. 3).

\section{Micro-environments}

For all six target species, radiation was significantly lower in DT and RT compared to OT (Table 1b). The radiation recorded in RT and DT was $81.3 \%$ and $72.2 \%$ lower compared to OT. Thus, in general, the DT canopy diminished radiation reaching the soil surface to a greater extent compared to the RT canopy (Table 1b). ANOVA results showed that species, treatments and species $\times$ treatment had significant effects on the majority of soil physicochemical properties except for Total P, Available P and soil bulk density (Table 1a). There were no significant differences in soil characters with or without the treatments before the planting $(\mathrm{P}>0.05)$. Soil nutrients tended to be improved by the shrub canopies or the practice of planting the native species except for $S$. wallichii. Overall, the microhabtitats beneath the nurse species canopies were markedly different from the open treatment with respect to soil properties and radiation. Based on the statistics, planting of the seedlings of $S$. wallichii and Cryptocarya chinensis also improved the soil nutrients (except for available $\mathrm{P}$ ) of the OT by a greater extent than other seedlings ( $d f$ $=17, P=0.000)$.

\section{Seedling leaf gas exchange and water potential}

There were no differences in gas exchange variables among the treatments $\left(L C P, R_{d}\right.$ and $\left.A Q Y\right)$, but $L S P(F=3.773$, $P=0.030)$ and $A_{\max }(F=3.409, P=0.041)$ differed (e.g. $L S P$ and $A_{\max }$ were higher in OT than in DT and RT for most species). Significant differences in each gas exchange characteristics $[\operatorname{LSP}(F=6.674, P=0.000), L C P(F=8.350, P=0.000)$, $R_{d}(F=6.386, P=0.000), A Q Y(F=3.015, P=0.017)$ and $A_{\max }$ $(F=5.896, P=0.000)]$ were found among the species. The differences in these variables also showed species $\times$ treatment interactions $(L S P, F=4.646, P=0.000 ; L C P, F=5.077, P=$ $0.000 ; R_{d}, F=3.431, P=0.001 ; A Q Y, F=2.670, P=0.007$; $\left.A_{\max }, F=4.832, P=0.001\right)$. For example, $P$. massoniana, $S$. heptaphylla, and $S$. wallichii had higher LSP, LCP and $A_{\max }$ compared to Cryptocarya chinensis and $C$. hystrix (Table 2). Leaf water potential varied similarly among the species for the different treatments over time. The results showed that the leaf water potential of all the species were lowest at the early stage and significantly increased over time (Fig. 4). There were also no treatment differences in water potential at the different growth stages for each species (Fig. 4). 
The relationship between environmental factors and seedling survival and growth

The RDA model indicated that seedling survival rates of P. massoniana, S. wallichii, C. hystrix, S. heptaphylla, Cryptocarya chinensis and Castanea chinensis were strongly and positively correlated with SOM and RA, total N, total P, SWC and SOM, pH and RA, and SWC and SBD respectively (Fig. 5). Furthermore, the soil properties, such as SWC, pH, total $\mathrm{N}$, total $\mathrm{P}$, and SBD, were strongly and positively correlated with the height of all target seedlings. The strongest positive factors affecting the biomass were RA for P. massoniana, C. hystrix and S. heptaphylla, SBD for S. wallichii and AK for Cryptocarya chinensis, and total $\mathrm{P}$ was a negative factor affecting the biomass of Castanea chinensis.

\section{Discussion}

Early successional species can play a key role in determining community assembly and successional trajectories. These roles are however strongly influenced by their interactions with other plant species (Callaway and Walker 1997). Overall, our results indicate that the effects of canopy treatments on seedling survival and growth were complex for the different target species. The survival rate was obviously lower for canopy treatments compared to OT plots in four out of the six species tested, while two of the six species showed positive effects of canopy on survival. $R$. tomentosa treatment had greater positive effects on survival compared to $D$. dichotoma treatment. This is probably because the dense canopy of the fern $D$. dichotoma is larger than that of $R$. tomento$s a$, (Table 1b). Several studies have shown that dense ferns
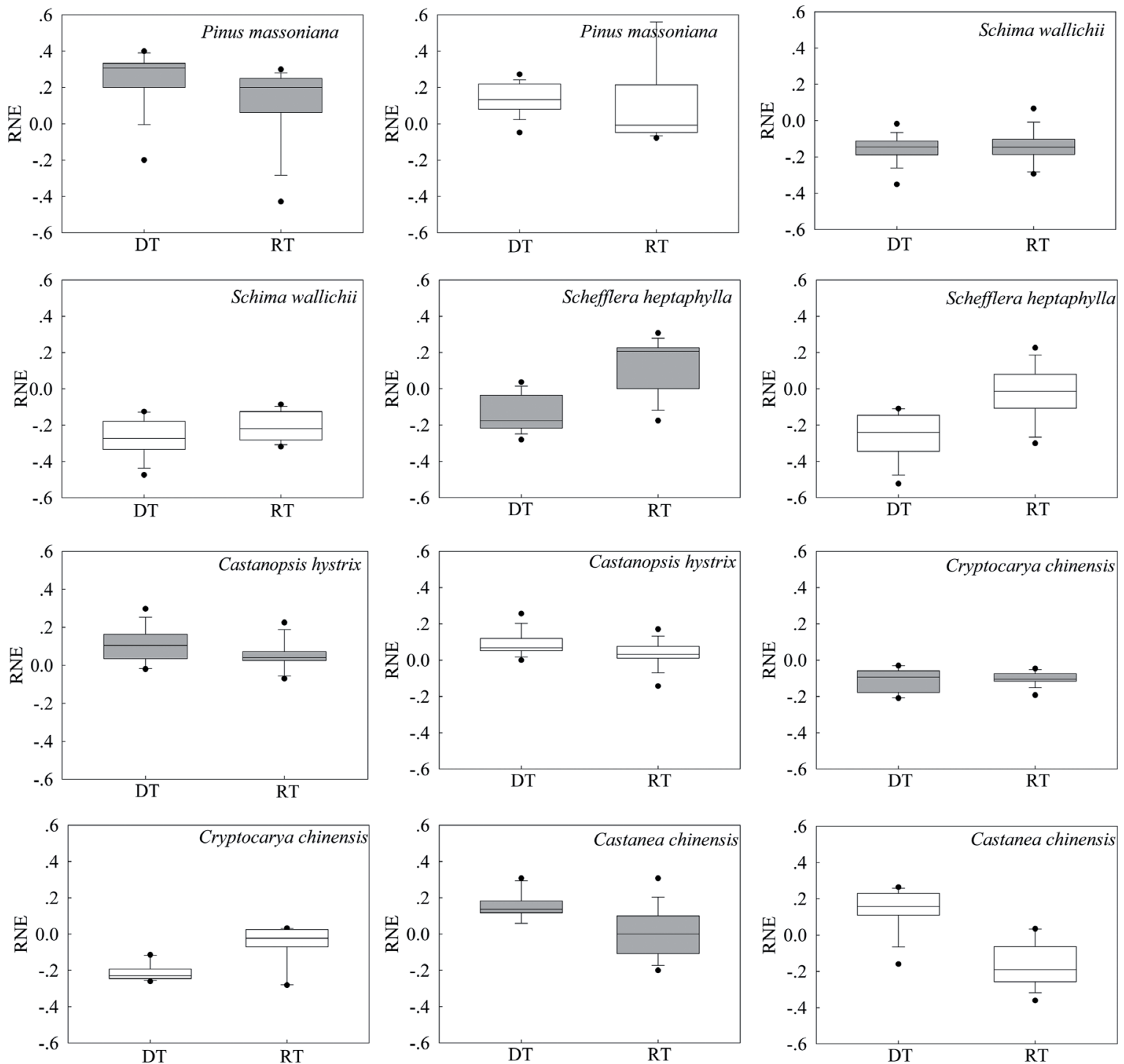

Figure 3. The relative neighbor effect index (RNE) of the shoot height of the six object species in the DT and RT plots after the first summer (shadow) and the second summer (open) in the field plots. The range in boxplots indicated the dispersion degree and deviation and the black points indicated the abnormal values for the RNE. When the RNE $<0$ showed the effect of the nurse plant on the target species was positive $(\mathrm{RNE}<0)$ or the $\mathrm{RNE}>0$ the effect was negative. 
Table 1. (a) Results of two-way ANOVA of the mean of the effect of species, treatment and species $\times$ treatments on soil properties. Significance values, $P<0.05$, in bold. (b) The statistics result of radiation among different species and treatments. Significant values, $P<0.05$, in bold.

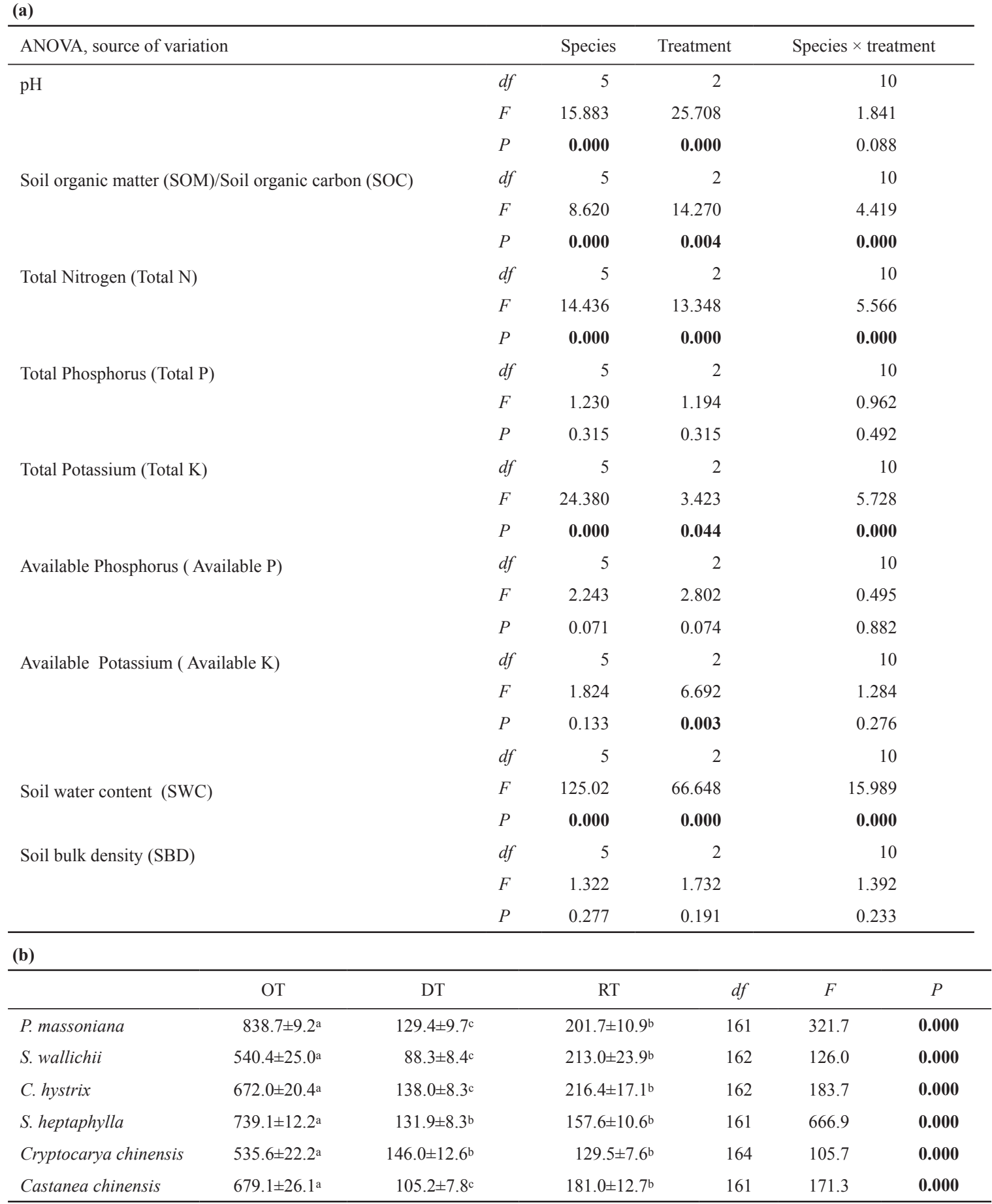

Notes: $\mathrm{RT}=R$. tomentos $a$ treatment, $\mathrm{DT}=D$. dichotom $a$ treatment, $\mathrm{OT}=$ open treatment

stands decreased both forb and woody plants richness compared to their removal, thereby inhibiting forest development. However, early successional woody plants in combination with tree ferns decreased species richness and cover of forbs but increased the richness of late-successional woody plants compared to their removal thereby facilitating long-term forest development (Walker et al. 2010, Walker et al. 1996). The negative effect of ferns may be due to rapid uptake and slow recycling of nutrients as well as the inhibition of tree seedling survival (Drake and Pratt 2001). Facilitative effects were also found, such as the negative RNE of seedling height in the RT and DT for most target species (Fig. 3). This leads us to conclude that under degraded moist conditions, such as the field sites in this study, the canopy treatment alone did 
Table 2. The leaf gas exchange characteristics dark respiration $(R d)$, apparent quantum yield $(A Q Y)$, the maximum photosynthetic rate (Amax), light compensation point $(L C P)$ and light saturation point $(L S P)$ of the six species seedlings

\begin{tabular}{|c|c|c|c|c|c|c|}
\hline Species & Treatments & $\begin{array}{c}R D \\
\left(\mathrm{MMOL} \mathrm{M}^{-2}\right. \\
\left.\mathrm{S}^{-1}\right)\end{array}$ & $A Q Y$ & $\begin{array}{c}A M A X \\
\left(\mathrm{MMOL} \mathrm{M}^{-2}\right. \\
\left.\mathrm{S}^{-1}\right)\end{array}$ & $\begin{array}{c}L C P \\
\left(\mathrm{MMOL} \mathrm{M}^{-2}\right. \\
\left.\mathrm{S}^{-1}\right)\end{array}$ & $\begin{array}{c}L S P \\
\left(\mathrm{MMOL} \mathrm{M}^{-2} \mathrm{~S}^{-1}\right)\end{array}$ \\
\hline \multirow[t]{3}{*}{ P. massoniana } & OT & $-3.0 \pm 0.7$ & $0.037 \pm 0.01$ & $18.0 \pm 5.7$ & $112.6 \pm 35.2$ & $2340.6 \pm 68.0$ \\
\hline & DT & $-1.9 \pm 0.2$ & $0.048 \pm 0.01$ & $8.0 \pm 1.5$ & $57.0 \pm 15.7$ & $958.6 \pm 340.0$ \\
\hline & RT & $-1.7 \pm 0.3$ & $0.051 \pm 0.01$ & $7.89 \pm 1.1$ & $47.2 \pm 7.4$ & $1032.3 \pm 152.5$ \\
\hline \multirow[t]{3}{*}{ S. wallichii } & OT & $-1.1 \pm 0.2$ & $0.06 \pm 0.01$ & $9 \pm 0.21$ & $24.0 \pm 4$ & $903.4 \pm 152.9$ \\
\hline & DT & $-1.3 \pm 0.22$ & $0.07 \pm 0.03$ & $8.0 \pm 1.4$ & $13.3 \pm 1.3$ & $803.5 \pm 230.9$ \\
\hline & $\mathrm{RT}$ & $-0.73 \pm 0.11$ & $0.02 \pm 0.01$ & $7.5 \pm 0.6$ & $13.33 \pm 9.6$ & $634.35 \pm 250.0$ \\
\hline \multirow[t]{3}{*}{ C. hystrix } & OT & $-1.7 \pm 0.2$ & $0.1 \pm 0.04$ & $6.4 \pm 0.6$ & $32 \pm 4$ & $642.6 \pm 111.4$ \\
\hline & DT & $-0.6 \pm 0.08$ & $0.05 \pm 0$ & $4.5 \pm 1.3$ & $13.3 \pm 1.3$ & 462. $6 \pm 165.3$ \\
\hline & $\mathrm{RT}$ & $-1.2 \pm 0.2$ & $0.04 \pm 0.02$ & $2.8 \pm 0.7$ & $46.7 \pm 10.9$ & $297.2 \pm 85.9$ \\
\hline \multirow[t]{3}{*}{ S. heptaphylla } & OT & $-1.3 \pm 0.2$ & $0.05 \pm 0$ & $12.8 \pm 1.3$ & $34.7 \pm 7.1$ & $1356.7 \pm 153.0$ \\
\hline & DT & $-1.9 \pm 0.3$ & $0.24 \pm 0.19$ & $11.8 \pm 1.8$ & $14.7 \pm 1.3$ & $1179.4 \pm 192.4$ \\
\hline & RT & $-1.1 \pm 0.2$ & $0.06 \pm 0.01$ & $11.3 \pm 0.6$ & $22.6 \pm 3.5$ & $1242.0 \pm 122.1$ \\
\hline \multirow{3}{*}{$\begin{array}{l}\text { Cryptocarya } \\
\text { chinensis }\end{array}$} & OT & $-0.8 \pm 0.1$ & $0.13 \pm 0.07$ & $5.7 \pm 2.0$ & $10.7 \pm 2.7$ & 477. $3 \pm 164.0$ \\
\hline & DT & $-0.8 \pm 0.2$ & $0.11 \pm 0.04$ & $3.9 \pm 0.3$ & $6.7 \pm 2.7$ & $295.8 \pm 45.5$ \\
\hline & $\mathrm{RT}$ & $-0.7 \pm 0.2$ & $0.06 \pm 0.01$ & $6.6 \pm 1.0$ & $13.3 \pm 1.3$ & $551.9 \pm 97.9$ \\
\hline \multirow[t]{3}{*}{ Castanea chinensis } & OT & $-2.0 \pm 0.9$ & $0.09 \pm 0.02$ & $6.76 \pm 1.2$ & $28 \pm 3.7$ & $898 \pm 268.5$ \\
\hline & DT & $-0.78 \pm 0.1$ & $0.03 \pm 0.01$ & $1.51 \pm 0.12$ & $41.33 \pm 17.5$ & $169.8 \pm 46.7$ \\
\hline & RT & $-1.54 \pm 0.7$ & $0.07 \pm 0.03$ & $9.45 \pm 1.5$ & $14.7 \pm 8.1$ & $606.4 \pm 212.7$ \\
\hline
\end{tabular}

Notes: $\mathrm{RT}=R$. tomentos $a$ treatment, $\mathrm{DT}=D$. dichotom $a$ treatment, $\mathrm{OT}=$ open treatment
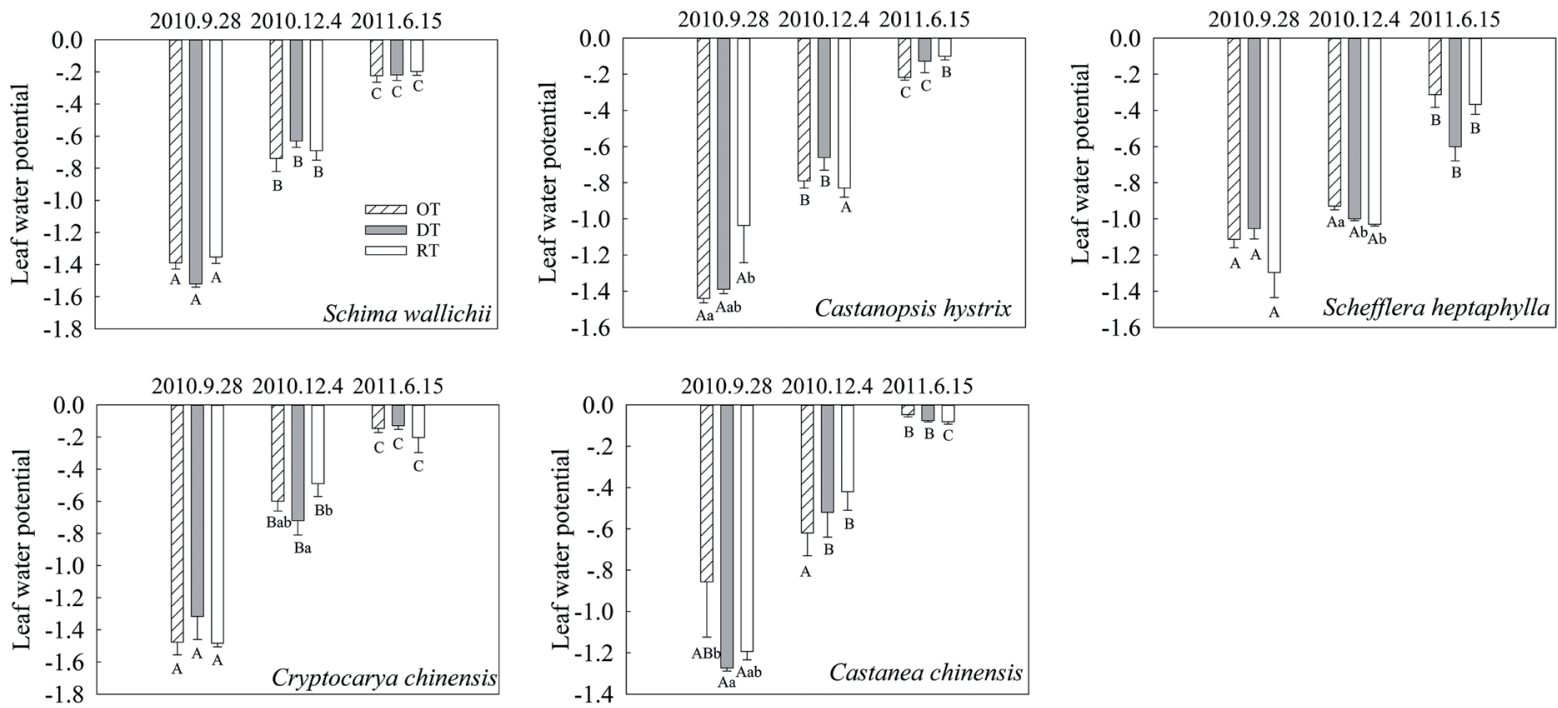

Figure 4. The leaf water potential changes of seedlings with time. Note that for P. massoniana, the leaf water potential was not measured due to practical reasons (i.e., conifer leaves are too small). Letters A, B and C indicate the differences of the leaf water potential between the different growth stage with the same treatment, $a, b$ and $c$ indicate the differences of the leaf water potential between the different treatments in the same growth stage.

not ensure the survival of all the seedlings, as other species seedlings were found when using the similar canopy treatment provided by the same shrubs in a nearby area (Yang et al. 2010). From January to March 2011, although we did observe some browsed shoots, particularly in the OT plots, the dense canopy shelters, especially the fern $D$. dichotoma, 

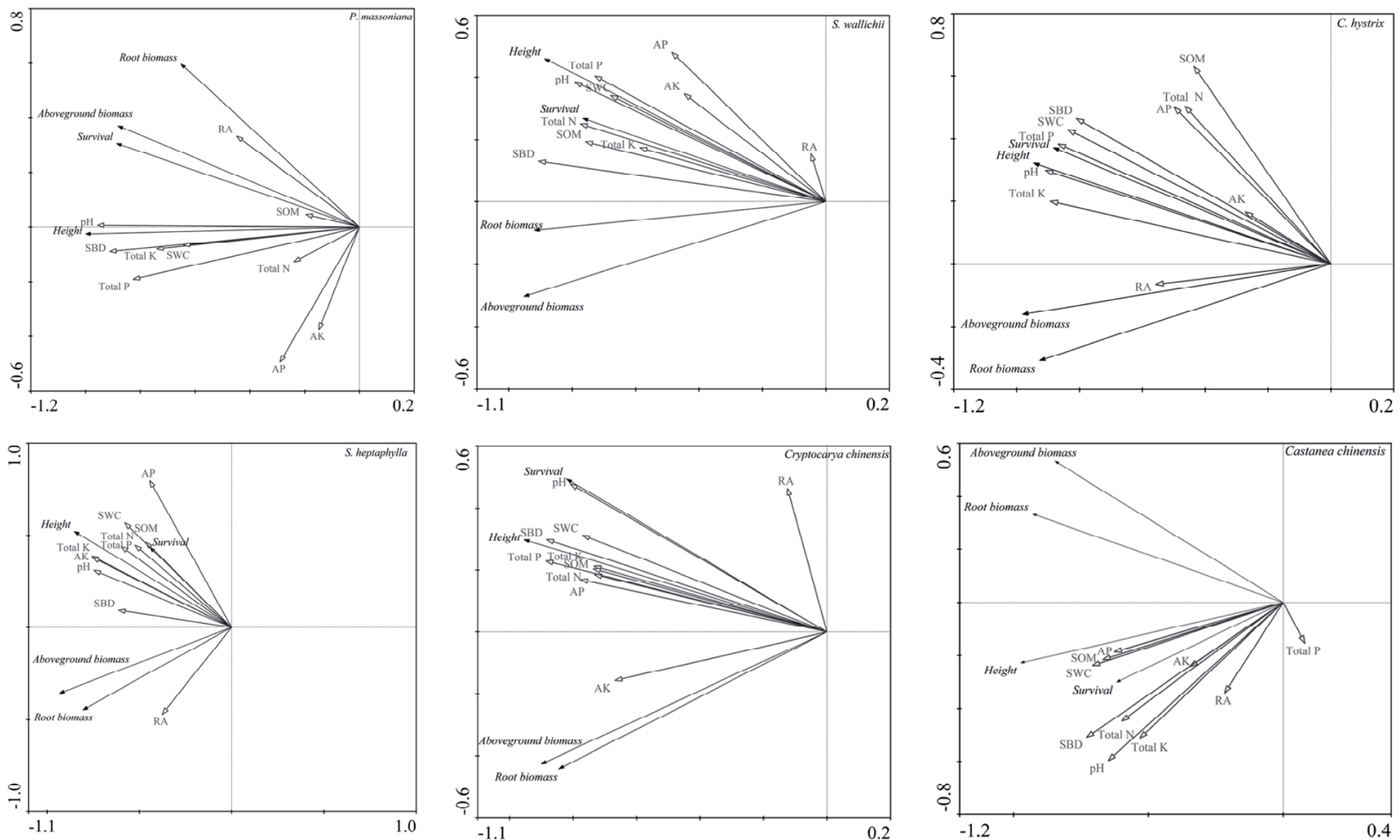

Figure 5. Canonical redundancy (RDA) bi-plots illustrating the effects of environmental factors on survival and growth (height, aboveground biomass and root biomass) of the six target seedlings. Red arrows indicate explanatory variables (environmental factors), while blue arrows indicate response variables for seedling survival and growth.

prevented rodents from feeding on the protected seedlings, even though we did not record levels of herbivory explicitly. S. heptaphylla and Cryptocarya chinensis were more protected from browsers in the DT compared with the RT and OT plots. These findings are in agreement with previous reports of indirect facilitation and its effects on plant communities in arid or semi-arid pastures or other ecosystems (Anthelmea and Michalet 2009, Oesterheld and Oyarzabal 2004, Smit et al. 2006). Thus, both species canopy treatments showed obvious beneficial effects on the growth of seedlings for most of the species.

Based on these experiments, we found that the irradiation and soil characteristics beneath the shrubs and ferns significantly differed from those in adjacent shrub-free and fern-free areas. We hypothesize that the shrubs and ferns were directly or indirectly responsible for the patterns detected in our study, and previous studies strongly supports this conclusion. Shrubs are well known to create distinct physical environments beneath their canopies, which, in turn, change irradiation, litter and soil characteristics (Callaway 1995, Holzapfel et al. 2006, Pugnaire et al. 1996, 2004, Scholes and Archer 1997, Shachak et al. 2008, Wright et al. 2006). The transmission of PAR to the ground surface remained consistently higher upon fern removal compared to the control plots, and this also could impact succession through the diminution of light levels (Walker et al. 2010). Our experiments reflected a decrease in light or irradiance, as a treatment effect, in both DT and RT plots (Table 1b). Several studies have shown that ferns are capable of extensively accumulating nutrients and are disproportional to their biomass (Drake and Pratt 2001, Russell et al. 1998), while their lignin-rich litter is often slow to decompose. In addition, they reduce nutrient loss by preventing soil erosion (Walker and Shiels 2008); hence they can serve as nutrient sinks for the ecosystem (Shiels et al. 2006, Walker et al. 2010). In our study, soils in the DT and OT plots had higher nutrient levels compared to OT plots, except for Total Phosphorus, Available P and soil bulk density. The planting of seedlings of S. wallichii and Cryptocarya chinensis also improved the soil nutrients in the OT plots (Table 1a). However, this observation needs further investigation.

In tropical or subtropical forests, irradiance is considered to be "the most limiting effect" (Pearcy 2007). However, our results showed that irradiation, soil nutrients and water content all had positive effects on the survival and growth of seedlings. This is consistent with a previous study conducted by Holste et al. (2011) which stated that the survival and growth of $45 \%$ of 94 seedling species were correlated with both irradiance and soil nutrients, $48 \%$ with soil nutrients, and rarely with irradiance alone. In our study, the survival and biomass of the light-demanding species P. massoniana, $C$. hystrix and $S$. heptaphylla were positively affected by irradiation. In addition, the survival and growth of other shade tolerant species correlated with at least one soil characteristics, and several soil nutrients had similar potential effects as irradiance. These species seedlings growing in low light levels may benefit from increased nutrient availability by increasing the light capture (Fahey et al. 1998). The leaf water potential results of seedlings showed that the seedlings suf- 
fered water stress at the initial stage (Fig. 4) due to the short drought in fall in our experimental sites. Thus, the canopy treatment may provide the optimal conditions for seedlings as it may contribute to maintaining soil moisture in open sites without imposing a severe low-light stress that restricts plant response to other potential stress (Rodríguez-Calcerrada et al. 2008). Plants' growth response to resources may be an important mechanism that influences species' distribution, coexistence, and community structure (Holste et al. 2011). The growth of both light demanding (most early and middle successional species) and shade-tolerant (most late successional species) seedlings respond to soil nutrients under high-light availability (Lawrence 2003), likely because faster growth increases demand for nutrients (Peace and Grubb 1982). Furthermore, the lower resource demand among shade-tolerant species may be a result of (1) greater seed nutrient reserves and/or (2) slower growth rates (Holste et al. 2011). In our study, the early successional species (such as $P$. massoniana and $S$. wallichii) showed higher gas exchanges and faster growth rates, while the later successional species showed lower gas exchange and slower growth rates (such as Cryptocarya chinensis and Castanea chinensis) (Fig. 1 \& Table 2). Additionally, the former species had smaller seed masses, while the later species had larger seed masses (Ren et al. 2010). However, the shade-tolerant species in this study tended to grow more slowly, and thus, would have lower demand for nutrient incorporation into new tissues. Our results are consistent with a broader trade-off between low-resource survival and high-resource growth (Kobe 1999, Kobe et al. 1995, Russo et al. 2008).

Predicting the seedling growth rate of the different canopy treatments under field conditions is important to understand forest succession and restoration. Although irradiance has been regarded as the primary determinant for seedling growth in wet tropical forests, soil nutrients are equally important. Our findings suggest that both canopy treatments enhanced seedling survival and growth consistently for most of the species planted in these moist sites. Fertile and moist soils occur underneath living nurse plants; hence, the conjunction of sheltered and fertile wet soils under the canopy of nurse plants may result in enhanced seedling survival and growth when compared to open sites. Despite these target species being well-adapted to the native climate, their seedlings may suffer from temporary water stress owing to the seasonally drought and browsing by rodents. The dense canopy of $D$. dichotoma may also act as an indirect nurse species protecting seedlings from damage. Different successional species can ensure their survival and growth with different physiological strategies to varying micro-habitats. Thus, the use of these tree shelter-types in similar environments should be reconsidered, especially under the present global weather change scenarios that have created drier conditions. They have been proven to largely contribute to the enhancement of seedling survival and growth, but often account for a significant proportion of the restoration budget. It is not surprising that ferns act as key nurse plants in these systems, given their rapid dispersal, tolerance for a variety of environmental conditions, competitiveness in utilizing available resources, and their indirect facilitation to late successional species, which may have been ignored in previous studies. Long-term observations and manipulations of succession will help identify critical steps in vegetation development and forest succession.

Acknowledgements: This research was supported by grants from the National Natural Science Foundation of China (No. 31270013). The authors are grateful to several colleagues at Heshan National Field Research Station of Forest Ecosystems, especially to Z. F. Lin, Z. A. Li and X. Gou for experimental design guidance; to H. L. Zhang for soil chemical analyses; and to B. Zou and G. Wang for field assistance.

\section{References}

Anthelmea, F. and R. Michalet. 2009. Grass-to-tree facilitation in an arid grazed environment (Aïr Mountains, Sahara). Basic Appl. Ecol. 10:437-446.

Bainbridge, D. 1994. Tree shelters improve establishment on dry sites. Tree Planters Note 45:13-16.

Bertness, M.D. and R.M. Callaway. 1994. Positive associations in communities. Trends Ecol. Evol. 9:191-193.

Brooker, R.W., F.T. Maestre, R.M. Callaway, C.L. Lortie, L.A. Cavieres, G. Kunstler, P. Liancourt, K. Tielboerger, J. Travis, F. Anthelme, C. Armas, L. Coll, E. Corcket, S. Delzon, E. Forey, Z. Kikvidze, J. Olofsson, F. Pugnaire, C.L. Quiroz, P. Saccone, K. Schiffers, M. Seifan, B. Touzard and R. Michalet. 2008. Facilitation in plant communities: the past, the present, and the future. J. Ecol. 96:18-34.

Bruno, J.F., J.J. Stachowicz and M.D. Bertness. 2003. Inclusion of facilitation into ecological theory. Trends Ecol. Evol. 18:119-125.

Callaway, R.M. 1995. Positive interactions among plants. Bot. Rev. 61:306-349.

Callaway, R.M. and L.R. Walker. 1997. Competition and facilitation: a synthetic approach to interactions in plant communities. Ecology 78:1958-1965.

Castro, J., R. Zamora and J.A. Hódar. 2004. Benefits of using shrubs as nurse plants for reforestation in Mediterranean mountains: a 4-year study. Restor. Ecol. 12:352-358.

Chaar, H., T. Mechergui, A. Khouaja and H. Abid. 2008. Effects of treeshelters and polyethylene mulch sheets on survival and growth of cork oak (Quercus suber L.) seedlings planted in northwestern Tunisia. Forest Ecol. Manag. 256:722-731.

Cushman, J.H., J.C. Waller and D.R. Hoak. 2010. Shrubs as ecosystem engineers in a coastal dune: influences on plant populations, communities and ecosystems. J. Veg. Sci. 21:821-831.

Drake, D.R. and L.W. Pratt. 2001. Seedling mortality in Hawaiian rain forests: the role of small-scale physical disturbance. Biotropica 33:319-323.

Drezner, T.D. 2007. An analysis of winter temperature and dew point under the canopy of a common Sonoran Desert nurse and the implications for positive plant interactions. J. Arid. Environ. 69:554-568.

Duan, W.J., H. Ren, S.L. Fu, Q.F. Guo and J. Wang. 2008. Pathways and determinants of early spontaneous vegetation succession in degraded lowland of South China. J. Integr. Plant Biol. 50: $147-156$.

Fahey, T.J., J.J. Battles and G.F. Wilson. 1998. Responses of early successional northern hardwood forests to changes in nutrient availability. Ecol. Monogr. 68:183-212. 
Francisco, M.P. and F.I. Pugnaire. 2010. Species identity and water availability determine establishment success under the canopy of Retama sphaerocarpa shrubs in a dry environment. Restor. Ecol. 17:900-907.

Gómez-Aparicio, L., R. Zamora, J.M. Gómez, J.A. Hódar, J. Castro and E. Baraza. 2004. Applying plant facilitation to forest restoration: A meta-analysis of the use of shrubs as nurse plants. Ecol. Appl. 14:1128-1138.

Holmgren, M. and M. Scheffer. 2010. Strong facilitation in mild environments: the stress gradient hypothesis revisited. J. Ecol. 98 1269-1275.

Holste, E.K., R.K. Kobe and C.F. Vriesendorp. 2011. Seedling growth responses to soil resources in the understory of a wet tropical forest. Ecology 92:1828-1838.

Holzapfel, C., K. Tielborger, H.A. Parag, J. Kigel and M. Sternberg. 2006. Annual plant-shrub interactions along an aridity gradient. Basic Appl. Ecol. 7:268-279.

Kitzberger, T., D.F. Steinaker and T.V. Veblen. 2000. Effects of climatic variability on facilitation of tree establishment in northern Patagonia. Ecology 81:1914-1924.

Kobe, R.K. 1999. Light gradient partitioning among tropical tree species through differential seedling mortality and growth. Ecology 80:187-201.

Kobe, R.K., J.A. Silander and C.D. Canham. 1995. Juvenile tree survivorship as a component of shade tolerance. Ecol. Appl. 5:517532.

Lawrence, D. 2003. The response of tropical tree seedlings to nutrient supply: meta-analysis for understanding a changing tropical landscape. J. Trop. Ecol. 19:239-250.

Lepš, J. and P. Šmilauer. 2003. Multivariate Analysis of Ecological Data Using CANOCO. Cambridge Univ. Press, Cambridge.

Liu, G.S. 1996. Soil physical and chemical analysis and description of soil profiles. Standards Press of China, Beijing, China.

Oesterheld, M. and M. Oyarzabal. 2004. Grass-to-grass protection from grazing in a semi-arid steppe. Facilitation, competition, and mass effect. Oikos 107:576-582.

Padilla, F.M., J.d.D. Miranda, R. Ortega, M. Hervás, J. Sánchez and F.I. Pugnaire. 2011. Does shelter enhance early seedling survival in dry environments? A test with eight Mediterranean species. Appl. Veg. Sci. 14:31-39.

Peace, W.J.H. and P.J. Grubb. 1982. Interaction of light and mineral nutrient supply in the growth of Impatiens parviflora. New Phytol. 90:127-150.

Pearcy, R.W. 2007. Responses of plants to heterogeneous light environments. In: Pugnaire F. and F. Valladares (Eds.), Functional Plant Ecology. Taylor \& Francis,New York, NY, USA, pp. 213258.

Peng, S.L., J. Liu and H.F. Lu. 2005. Characteristics and role of Acacia auriculiformis on vegetation restoration in lower subtropics of China. J. Trop. For. Sci. 17:508-525.

Pugnaire, F.I., C. Armas and F. Valladares. 2004. Soil as a mediator in plant-plant interactions in a semi-arid community. J. Veg. Sci.15:85-92.

Pugnaire, F.I., P. Haase, J. Puigdefabregas, M. Cueto, S.C. Clark and L. Incoll. 1996. Facilitation and succession under the canopy of a leguminous shrub, Retama sphaerocarpa, in a semi-arid environment in south-east Spain. Oikos 76:455-464.
Ren, H., X.A. Cai, C.H. Li and Y.S. Ye. 2010. Atlas on Tool Species of Vegetation Recovery in South China. Huazhong University of Science \& Technology Press, Wuhan.

Rey-Benayas, J.M. 1998. Growth and survival in Quercus ilex L. seedlings after irrigation and artificial shading on Mediterranean set-aside agricultural land. Ann. Sci. Forest. 55:801-807.

Rodríguez-Calcerrada, J., J.A. Pardo, L. Gil and I. Aranda. 2008. Ability to avoid water stress in seedlings of two oak species is lower in a dense forest understory than in a medium canopy gap. Forest Ecol. Manag. 255:421-430.

Russell, A.E., J.W. Raich and P.M. Vitousek. 1998. The ecology of the climbing fern Dicranopteris linearis on windward Mauna Loa, Hawaii. J. Ecol. 86:765-779.

Russo, S.E., P. Brown, S. Tan and S.J. Davies. 2008. Interspecific demographic trade-offs and soil-related habitat associations of tree species along resource gradients. J. Ecol. 96:192-203.

Scholes, R.J. and S.R. Archer. 1997. Tree-grass interactions in savannas. Annu. Rev. Ecol. Syst. 28:517-544.

Shachak, M., B. Boeken, E. Groner, R. Kadmon, Y. Lubin, E. Meron, G. Ne'Eman, A. Perevolotsky, Y. Shkedy and E.D. Ungar. 2008. Woody species as landscape modulators and their effects on biodiversity patterns. BioScience 58:209-221.

Sharrow, S.H. 2001. Effects of shelter tubes on hardwood tree establishment in western Oregon silvopastures. Agroforest. Syst. 53:283-290.

Shiels, A.B., L.R. Walker and D.B. Thompson. 2006. Organic matter inputs create variable resource patches on Puerto Rican landslides. Plant Ecol. 184:223-236.

Smit, C., J. DenHouden and H. Müller-Schärer. 2006. Unpalatable plants facilitate tree sapling survival in wooded pastures. J. Appl. Ecol. 43:305-312.

Walker, L.R., F.H. Landau, E. Velázquez, A.B. Shiels and A.D Sparrow. 2010. Early successional woody plants facilitate and ferns inhibit forest development on Puerto Rican landslides. $J$. Ecol. 98:625-635.

Walker, L.R. and A.B. Shiels. 2008. Post-disturbance erosion impacts carbon fluxes and plant succession on recent tropical landslides. Plant Soil. 313:205-216.

Walker, L.R., D.J. Zarin, N. Fetcher, R.M. Myster and A.H. Johnson. 1996. Ecosystem development and plant succession on landslides in the Caribbean. Biotropica 28:566-576.

Wright, J.P., C.G. Jones, B. Boeken and M. Shachak. 2006. Predictability of ecosystem engineering effects on species richness across environmental variability and spatial scales. J. Ecol. 94:815-824

Yang, L., N. Liu, H. Ren and J. Wang. 2009. Facilitation by two exotic Acacia: Acacia auriculiformis and Acacia mangium as nurse plants in South China. Forest. Ecol. Manag. 257:1786-1793.

Yang, L., H. Ren, N. Liu and J. Wang. 2010. The shrub Rhodomyrtus tomentosa acts as a nurse plant for seedlings differing in shade tolerance in degraded land of South China. J. Veg. Sci. 21:262272 .

Received June 23, 2017 Revised July 31, 2018, December 20, 2018 Accepted January 1, 2019 